\title{
Actualización Consenso Neumonía asociada a ventilación mecánica. Segunda parte. Prevención
}

\author{
Mario Calvo A., Luis Delpiano M., Eliana Chacón V., M. Irene Jemenao P., \\ Anamaría Peña D. y Alejandra Zambrano G.
}

\begin{abstract}
Universidad Austral de Chile, Valdivia (MCA).

Hospital San Borja Arriarán, Santiago (LDM).

Hospital Padre Hurtado,

Santiago.

Enfermera Control de IAAS (ECV). Hospital Clínico Universidad de Chile, Santiago, Chile (MIJP).

Enfermera Control de IAAS

Hospital Dr. Sotero Del Río, Santiago y Sociedad Chilena de Pediatría (APD).

Hospital Clínico Universidad Católica

Enfermera Control de IAAS (AZG). Sociedad Chilena de

Infectología, Comité Consultivo IIH (LDM, ECV, MIJP, AZG).

*Documento elaborado por el grupo de trabajo sobre prevención de neumonía asociada a ventilación mecánica. Presentado en parte en el XXVI Congreso Chileno de Infectología, Viña del Mar, octubre de 2009.

Recibido: 18 de abril de 2011

Conflicto de interés para cualquier autor: ninguno

Fuente de financiamiento: ninguna
\end{abstract}

Correspondencia a: Mario Calvo Arellano macalvo@uach.cl.

\section{Introducción}

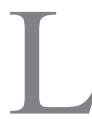

a neumonía asociada a ventilación mecánica (NAVM) se mantiene como una entidad de alta mortalidad que afecta a las poblaciones sometidas a este procedimiento. A pesar de que se han diseñado estrategias para iniciar un tratamiento oportuno y apropiado, mejorando el pronóstico de mortalidad de los enfermos, no es menos cierto que la mortalidad atribuible es aún elevada con una terapia adecuada. Por esto, el desarrollo y ejecución de medidas de prevención adecuadas parece ser uno de los esfuerzos más acertados para la disminución de la morbi-mortalidad asociada a este cuadro.

En los últimos nueve años, el desarrollo de la literatura científica enfocada a este aspecto ha sido enorme y muy variado, incluyendo nuevos tipos de intervenciones, a la vez que ha intentado esclarecer la utilidad de las más antiguas; por otro lado, en otras se ha logrado tener un mejor dato respecto a su evidencia, así como en algunas, por el poco tiempo de desarrollo que llevan, no ha sido posible dar una recomendación con la misma calidad de fundamento.

Como se ha mencionado previamente, este artículo es parte de la actualización del consenso realizado, con anterioridad, por la Sociedad Chilena de Infectología en el año 2001. La metodología nuevamente ha buscado realizar recomendaciones basadas en la evidencia que se han tabulado según lo indicado en la Tabla 1, y pretende, además, ver la factibilidad de la aplicación de estas medidas al medio nacional.

\section{Métodos}

La metodología general ya ha sido descrita, pero para los fines de búsqueda, se diseño un grupo de preguntas sugeridas por uno de los autores (LDM), lo cual fue revisado y corregido posteriormente por el resto del grupo. Luego, las preguntas fueron distribuidas para trabajarlas por dos autores cada una, quienes debían realizar una búsqueda focalizada hacia ese aspecto. Esa búsqueda fue complementada además con una búsqueda amplia realizada en mayo de 2009 en www.pubmed.org con los términos "ventilator associated pneumonia OR (mechanical ventilation AND pneumonia) AND prevention", seleccionando datos entre los años 2000 y 2009, la cual originó 887 artículos que fueron revisados en forma de abstract para escoger los que fueran atingentes. Estos últimos fueron, 
en general, seleccionados para su revisión en texto completo con algunas excepciones en que se debió revisar el resumen, específicamente al tratarse de literatura en que el idioma original correspondía a lenguas orientales. Las conclusiones fueron inicialmente entregadas en una sesión especial en el Congreso Chileno de Infectología del año 2009 para su discusión. Posteriormente, las conclusiones fueron presentadas en el grupo completo de neumonía asociada a ventilación mecánica en enero de 2010 con representantes de las tres ramas del consenso (prevención, diagnóstico y tratamiento) y debatidas para obtener una conclusión final. Luego se realizó una nueva revisión final de los textos por parte de los encargados de cada rama para depurar las recomendaciones entregadas y enviar a publicación. Se asignó a cada recomendación un nivel de evidencia y fuerza de la recomendación, utilizando la misma escala utilizada en el consenso anterior ${ }^{1}$, las que fueron contempladas por todos los autores para evaluar su acuerdo con la decisión.

\section{Resultados}

A continuación se entregan los resultados obtenidos para cada uno de los temas que involucró el consenso.

\section{¿Influye la posición de la cama en la aparición de neumonía asociada a ventilación mecánica?}

El mantener al paciente en posición semisentada para disminuir la posibilidad de que se produzca entrada de secreciones procedentes del tracto digestivo a la vía respiratoria, es una de las formas más simples de prevención de NAVM. Este tópico ha sido analizado en un trabajo controlado, randomizado, ya analizado en el consenso anterior, el que mostró una disminución de la incidencia de neumonía, siendo la disminución de 34 a $8 \%{ }^{2}$. Este trabajo había sido precedido de otro de tipo experimental realizado en 19 pacientes intubados, en los que se administraba Tc99 a nivel gástrico, y posteriormente se determinaba que existía una disminución significativa en los recuentos de radioactividad que presentaban las secreciones bronquiales en los pacientes al adoptar la posición semisentada ${ }^{3}$.

Recientemente se agregó un meta-análisis que incluyó tres trabajos, analizando la posición semisentado en $45^{\circ}$, versus la posición supina ${ }^{4}$. Éste demostró una disminución en la incidencia de la NAVM con un OR de 0,47 (IC 95\% de 0,27 a 0,82 ) para una población de 337 pacientes. Los antecedentes actuales permiten sostener que se recomienda la posición semisentada a $45^{\circ}$ con un nivel de evidencia y de recomendación IA.

Se ha analizado también la posibilidad de que haya diferencias entre mantener al paciente semisentado a $30^{\circ}$ o a $45^{\circ}$, tema que fue analizado en un trabajo controlado ${ }^{5}$,
Tabla 1. Grado de recomendación y calidad de la evidencia

\begin{tabular}{|c|c|}
\hline Grado de recomendación & Definiciones \\
\hline A & Buena evidencia para recomendar su uso \\
\hline B & Moderada evidencia para recomendar su uso \\
\hline C & Pobre evidencia para recomendar su uso \\
\hline D & Moderada evidencia para desaconsejar su uso \\
\hline$E$ & Buena evidencia para desaconsejar su uso \\
\hline Calidad de la evidencia & Clasificación \\
\hline I & Uno o más trabajos prospectivos randomizados y controlados \\
\hline$\|$ & $\begin{array}{l}\text { Uno o más estudios clínicos no randomizados; uno o más estudios } \\
\text { de cohorte o caso-control (idealmente multicéntrico); múltiples } \\
\text { series de casos; o experimentos no controlados con resultados } \\
\text { significativos }\end{array}$ \\
\hline III & $\begin{array}{l}\text { Opiniones de expertos, basados en experiencias clínicas, estudios } \\
\text { descriptivos o reportes de comités }\end{array}$ \\
\hline
\end{tabular}

no encontrándose diferencias significativas en las tasas de NAVM entre ambos grupos. No obstante, la diferencia en el promedio de reclinación entre ambos grupos, el cual fue medido sistemáticamente, tampoco difirió significativamente, lo que no permite asegurar si la posición a $45^{\circ}$ sería o no más segura realmente. Por tanto, se recomienda mantener al paciente semisentado en $45^{\circ}$, aunque no existen claras ventajas de la mayor reclinación.

Otros autores han señalado algunas circunstancias en que se quiebra esta técnica (por ejemplo: al hacer el punto 0 para la medición de la presión venosa central o al enviar al paciente a una tomografía computada) como maniobras que podrían poner al paciente en riesgo de desarrollar una NAVM. Lamentablemente, no hay estudios que puedan objetivar este punto, por lo que no se puede hacer una recomendación respecto a prohibir absolutamente maniobras que interfieran con la posición semisentado (IIIC). A pesar de ello, se hace énfasis en mantener la posición semisentada todo el tiempo que sea posible.

\section{La incorporación de camas rotatorias en la Unidad de Cuidados Intensivos (UCI) ¿es una intervención útil para prevenir la NAVM?}

El uso de las camas rotacionales y sus distintos efectos han sido investigados, in extenso, en una revisión y meta-análisis por Goldhill y cols ${ }^{6}$, que incluyó un grupo de 16 estudios prospectivos controlados; 12 evaluaron el uso de las camas rotacionales. Estos estudios tienen algunas limitantes como: no ser de tipo doble ciego (dada la naturaleza del estudio), el usar diferentes protocolos de rotación muchas veces no descritos en la metodología, uso de distintos tipos de camas rotacionales, ausencia de detalles sobre el manejo del grupo control, ni en qué grado se encontraban semisentados los pacientes de ambos 
grupos y finalmente, el método de randomización. El meta-análisis sugiere una disminución en la incidencia de NAVM pero no se hizo una cuantificación de este efecto. No hubo diferencia alguna en la estadía en UCI, en los días en ventilación mecánica ni en la mortalidad. Si bien el análisis de costos no muestra un valor significativamente mayor, la adquisición de estas camas es de alto costo.

En vista de la falta de datos que apoyen significativamente la eficacia en esta intervención, este consenso no recomienda por ahora la incorporación de este tipo de camas en las UCIs (IID).

\section{La incidencia de NAVM ¿tiene relación con el tipo de fármaco utilizado para prevenir la hemorragia digestiva alta?}

La decisión del uso de profilaxis para hemorragia digestiva alta (HDA) ha sido un tema controversial y de amplio estudio en la década de los ' 90 pero aún persisten temas en discusión. La incidencia de esta complicación se ha estimado en un rango de 0,6 a $6 \% \% \%^{7-9}$. Así por ejemplo, en un estudio canadiense, en que la HDA fue clasificada en dos categorías: abierta (cuando había hematemesis o aspiración de sangre por el catéter nasogástrico) o clínicamente importante (cuando el sangrado se asociaba a hipotensión arterial y a una transfusión mínima de dos unidades de eritrocitos), la incidencia de HDA abierta fue de $9 \%$ y la de HDA clínicamente importante sólo de $2 \%$. En este estudio, la estadía en UCI atribuible a HDA clínicamente importante fue de 6,5 días con un riesgo relativo de mortalidad de $12,5 \%$.

Un aspecto polémico es que, a pesar de que la profilaxis de HDA es ampliamente utilizada en el mundo, su efectividad en la disminución de mortalidad del paciente crítico no ha sido fehacientemente demostrada ${ }^{8}$. En consecuencia, se debe asegurar que la prevención de la HDA no produzca un mayor riesgo de NAVM llevando a un daño mayor o igual al potencial beneficio de esta profilaxis. En este sentido, en los '90 se realizaron varios meta-análisis intentando demostrar cuales agentes aseguraban una profilaxis adecuada de HDA y, a la vez, que el aumento del $\mathrm{pH}$ intragástrico inducido por estas intervenciones, no llevase en forma secundaria a un aumento en la incidencia de NAVM, sin embargo, se obtuvieron resultados contradictorios ${ }^{8,10}$. Posteriormente, Cook y cols, publicaron un extenso ensayo controlado, randomizado, comparando sucralfato (que no aumenta el pH intragástrico) con ranitidina (que sí lo aumenta) ${ }^{11}$ incluyendo 1.200 pacientes. Este estudio demostró que el grupo que recibió ranitidina tenía una menor incidencia de $\operatorname{HDA}(1,7$ versus $3,8 \%$; $p$ $0,02)$, sin haber diferencias en la incidencia de NAVM, ni en la mortalidad. Este estudio es, posiblemente, el que más influencia ha tenido en las recomendaciones posteriores. Se han comunicado además, algunos ensayos en pacientes hospitalizados evaluando la utilidad comparativa de los in- hibidores de la bomba de protones, como fuera un estudio controlado de Levy y cols ${ }^{12}$, en una pequeña muestra de pacientes en que comparó la efectividad de la profilaxis con ranitidina y omeprazol, encontrando una incidencia de hemorragia digestiva de 31 y $6 \%$, respectivamente ( $p$ $<0,05)$. Otro ensayo controlado, randomizado ${ }^{13}$, comparó el uso de ranitidina, sucralfato y omeprazol registrando frecuencias de hemorragia digestiva en $10,5 \%, 9,3$ y $0 \%$, respectivamente, no siendo esta diferencia significativa.

Otro estudio controlado, randomizado ${ }^{14}$, efectuado en niños en ventilación mecánica evaluó los efectos de la profilaxis en cuatro grupos de pacientes asignados, ya fuese a sucralfato, ranitidina, omeprazol o ningún tratamiento, sobre la incidencia de NAVM y la mortalidad, no encontrando diferencias significativas en ninguno de los dos resultados: 42, 48, 45 y $41 \%$, respectivamente, para NAVM con un p: 0,963 y 21, 23, 21 y $21 \%$, respectivamente, para cada grupo en el caso de la mortalidad (p: 0,98).

Un estudio de análisis de decisión ${ }^{15}$ basado en un modelo predictor logístico sobre una cohorte ficticia de pacientes en ventilación mecánica, con duración esperada superior a $48 \mathrm{hrs}$, y utilizando las probabilidades estimadas de la literatura científica publicada, evaluó la reducción de la mortalidad con profilaxis mediante bloqueadores $\mathrm{H}_{2}$ versus placebo, asignando un riesgo basal de acuerdo a los datos de las publicaciones. Se encontró una expectativa basal de mortalidad de $16,6 \%$ en el grupo tratado y $16,9 \%$ en el grupo placebo, con una diferencia de riesgo de $0,3 \%$, lo que no resultó significativo y que, por lo tanto, no permite marcar una preferencia sobre estos medicamentos o que su uso vaya a alterar la mortalidad de los pacientes al interior de la UCI.

Este consenso considera de esta manera, que tanto los inhibidores de los receptores $\mathrm{H} 2$, como el sucralfato, o el omeprazol pueden ser utilizados con equivalente riesgo de neumonía en la profilaxis de HDA (IA). No obstante, la menor efectividad de sucralfato apunta hacia la utilización preferente de los dos primeros agentes. El costo menor de los bloqueadores anti-H2 es un punto importante para considerar su uso mayor. El decidir las mejores indicaciones para el uso de profilaxis está fuera de los objetivos de este consenso.

\section{El uso de sonda nasoyeyunal respecto a sonda nasogástrica ¿logra disminuir la incidencia de NAVM?}

Los modelos de patogenia de la neumonía nosocomial apuntan a que ésta se inicia por la colonización del estómago con microbiota potencialmente patógena, la que por reflujo gastroesofágico (RGE) alcanza la orofaringe, desde donde llega a la vía aérea por microaspiraciones que fluyen alrededor del tubo endotraqueal. 
Por otro lado, la nutrición de un paciente críticamente enfermo es fundamental para su recuperación y la alimentación enteral es, en general, preferible a la parenteral. La alimentación enteral favorece, sin embargo, la colonización gástrica con microorganismos potencialmente patógenos, porque alcaliniza el estómago y favorece el RGE por distensión gástrica y la presencia de tubos de alimentación.

El consenso de NAVM publicado anteriormente concluyó, a la luz de la evidencia disponible, que no se había logrado establecer diferencias significativas entre la ubicación gástrica y duodenal para decidir la instalación de la sonda de alimentación enteral ${ }^{16}$. Desde entonces, se han agregado a la literatura científica dos meta-análisis, que evaluaron el potencial de la alimentación precoz post pilórica en la reducción de la incidencia de NAVM. Estos meta-análisis ${ }^{17,18}$, realizados en pacientes adultos de UCI, no mostraron ventajas de la alimentación transpilórica sobre la gástrica en relación a la incidencia de neumonía por aspiración (RR 1,28 - IC 95\% 0,91-1,80), mortalidad (RR 1,01 - IC 95\% 0,76 - 1,36) o estadía en UCI.

Por lo tanto, este consenso recomienda que la alimentación enteral pueda realizarse indistintamente tanto por sonda gástrica como post-pilórica (IA).

\section{La alimentación enteral fraccionada ¿conlleva un menor riesgo de NAVM?}

Varios trabajos aparecidos en los últimos años sugieren que lo más relevante en la alimentación enteral es evitar la sobre-distensión gástrica. Para lograrlo, es importante la monitorización intermitente de los residuos de contenido, los que impactarían en la incidencia de NAVM ${ }^{19,20}$.

Por tanto, independientemente a usar la ubicación gástrica o post-pilórica de alimentación, este consenso considera importante el uso de cantidades moderadas de alimentación controlando la existencia de residuos para evitar la sobre-distensión abdominal (IIB).

\section{El uso de descontaminación selectiva con antimicrobianos ¿es útil para prevenir la NAVM?}

La incorporación de los procedimientos de descontaminación selectiva ha sido uno de los temas más polémicos en las unidades de cuidados intensivos ${ }^{21}$. En forma progresiva, los meta-análisis han ido mostrando una disminución neta de la frecuencia de NAVM y, en los últimos años, la acumulación de la información ha mostrado una disminución global de la mortalidad en UCI. De los nueve meta-análisis realizados, el más completo corresponde al de la colaboración Cochrane, el que fue usado como referencia para este tópico ${ }^{22}$. En 26 de los 36 (el resultado infección respiratoria fue analizado sólo en 33)" estudios incluidos en esta revisión sistemática que analiza el uso de la profilaxis antimicrobiana en pacientes hospitalizados en UCIs, la totalidad de los pacientes se encontraba en ventilación mecánica. Este estudio concluye que la aplicación de la descontaminación antimicrobiana tópica disminuye la incidencia de NAVM, pero no la mortalidad, requiriéndose tratar siete pacientes para prevenir un cuadro de neumonía. Para el caso de la profilaxis con soluciones tópicas asociados a antimicrobianos de uso sistémico, se estimó que se requería tratar a cuatro pacientes para la prevención de un episodio de NAVM, y que al realizarla a 18 pacientes se lograba prevenir un fallecimiento.

Ha sido muy discutido en la literatura médica que siendo una técnica con disminución demostrada en la mortalidad, no haya sido incorporada al manejo de los enfermos. Basándose en opiniones de expertos, se ha señalado una importante preocupación respecto al desarrollo de resistencia bacteriana como consecuencia del uso de estas soluciones, aspecto que ha sido pobremente evaluado en los estudios ${ }^{21}$. En el meta-análisis ya mencionado, sólo en un estudio se evaluó esta hipótesis no demostrando mayor resistencia y no se menciona el tópico en el resto de los estudios. Un estudio reciente realizado en unidades de cuidados intensivos en los Países Bajos ${ }^{23}$, evaluó la colonización por bacterias multi-resistentes en la faringe y torulado rectal, sin encontrar mayor incidencia de ellas en pacientes con descontaminación tópica o sistémica. No obstante, al revisar con más detalle, hay trabajos que mencionan cambios en la ecología de la unidad ${ }^{24}, y$ en otro estudio hubo una tendencia en el grupo tratado a una mayor frecuencia de neumonía estafilocóccica ${ }^{25}$. Lingnau $\mathrm{W}$, en un reporte posterior al trabajo original, menciona la aparición de Acinetobacter calcoaceticus multi-resistente en el grupo tratado, al año de uso, aunque no estadísticamente significativo, y un aumento relativo de las infecciones por microorganismos grampositivos ${ }^{26}$. Otro reporte señala la presencia de una mayor colonización por Staphylococcus coagulasa negativa ${ }^{27}$, aunque no se mencionan consecuencias clínicas de este hallazgo. En otro trabajo se menciona que en el grupo tratado con descontaminación se encontró una mayor frecuencia de microorganismos resistentes a tobramicina y cefotaxima ${ }^{28}$. No obstante, no hay datos clínicos que demuestren la verdadera relevancia de estos hallazgos en las respectivas unidades a largo plazo. Sólo es interesante mencionar que Sánchez García M., que describió el uso de la descontaminación en 1998 en tres centros, concluyendo que su grupo era partidario del uso de descontaminación en vista del beneficio en frecuencia de neumonía y mortalidad, también señaló que se presentaba una mayor prevalencia de colonización por cocáceas grampositivas (suma de Staphylococcus aureus, Staphylococcus coagulasa negativa y Enterococcus spp ${ }^{29}$. El mismo autor reportó el año 2010 el primer brote de $S$. aureus resistente a linezolid, pero no se señala en la descripción del centro si se hacía o no uso de descontaminación ${ }^{30}$. 
En los países en que se ha popularizado el uso de la descontaminación, se utiliza en forma tópica como pastas de colistin, tobramicina y anfotericina B y para el uso sistémico en casi todos los trabajos se ha utilizado cefotaxima endovenosa.

Por otra parte, la situación actual en Chile plantea ciertas dificultades ya que expone a los microorganismos al colistin, siendo que para muchas unidades de nuestro país, es el único agente efectivo sobre cepas de P. aeruginosa. Asimismo, la mayoría de los reportes exitosos corresponden a unidades con bajas tasas de endemia por $S$. aureus resistente a meticilina y Enterococcus resistente a vancomicina, lo que ha sido destacado en varios comentarios $^{31}$.

En estas condiciones, este consenso no recomienda el uso de la descontaminación selectiva en las UCIs en Chile (IID). No obstante, su uso sería postulable en el caso de unidades de cuidados intensivos que no tengan cepas de $P$. aeruginosa pan-resistente, que tengan además una baja prevalencia de $S$. aureus resistente a meticilina y que no tengan endemia de Enterococcus spp resistente a vancomicina. Este panorama se encuentra en muchos países del norte de Europa donde esta técnica ha sido más eficaz.

\section{La higiene rutinaria de la cavidad oral ¿es de utilidad para prevenir la NAVM?}

Considerando que el desarrollo de NAVM requiere la presencia de patógenos que accedan al tracto respiratorio inferior cuyas fuentes primarias son el tracto respiratorio superior y el tubo digestivo, la prevención de la colonización de estos sitios representa un blanco potencial para su prevención. En este sentido, se ha estudiado la descontaminación oral con varios antisépticos como iseganan, clorhexidina y povidona yodada. Los resultados con ellos se comentan a continuación.

Iseganan: Un estudio randomizado ${ }^{32}$ no demostró impacto en la prevención de NAVM cuando se comparó iseganan con placebo. La muestra fue un grupo de 709 pacientes randomizados a intervención (n: 362) o placebo (n: 347). La tasa de NAVM en el grupo tratado fue 16 versus $20 \%$ en el grupo placebo (p 0,145; $\mathrm{IC}_{95}-10.4 \mathrm{a}+$ 2.2). No hubo diferencia en mortalidad y no hubo efectos adversos.

Povidona yodada: Su eficacia en la disminución de la NAVM fue demostrada en un pequeño estudio randomizado $^{33}$ en pacientes con trauma cerebral grave (Glasgow $<8$ ), pero no ha sido evaluada en otros pacientes. El estudio incluyó un grupo de 36 pacientes en los que se usó enjuague bucal con $20 \mathrm{ml}$ de povidona yodada al 10\% en solución acuosa reconstituida en $60 \mathrm{ml}$ de agua estéril (grupo povidona yodada), para luego realizar una aspiración oro-faríngea. El segundo grupo estuvo constituido por 31 pacientes a los que se les realizó enjuague naso- faríngeo y oro-faríngeo con $60 \mathrm{ml}$ solución salina, seguida de aspiración oro-faríngea (grupo salino) y finalmente, un tercer grupo (control) de 31 pacientes al que sólo se le hizo aspiración oro-faríngea. Estos procedimientos fueron aplicados cada $4 \mathrm{hrs}$. La prevalencia de NAVM en los grupos solución salina y control no fue diferente ( $\mathrm{p}$ : $0,796)$, pero en el grupo povidona la reducción de riesgo relativo fue de $80 \%$ ( $8 \%$ para el grupo povidona versus $39 \%$ en el grupo solución salina y $42 \%$ en el grupo sin intervención). La reducción en el riesgo de NAVM no se acompañó de diferencias en la estadía hospitalaria ni en la mortalidad, ya que fue similar en los tres grupos. No hubo eventos adversos asociados al uso de povidona. Se debe señalar que este estudio tiene varias limitaciones que incluyen su naturaleza no ciega, la alta prevalencia de NAVM en la población estudiada y que, por otra parte, estuvo asociada a un patrón de colonización propio de microorganismos adquiridos en la comunidad. En vista del tipo de población, los resultados no pueden extrapolarse. No se evaluó el efecto del uso prolongado de povidona en la microbiota endógena.

Se cuenta también con los resultados obtenidos de un estudio observacional ${ }^{34}$ que analizó controles históricos y los comparó con 1.252 pacientes en UCI conectados a ventilación mecánica, en los que se evaluó un protocolo de higiene oral con aspiración de secreciones, povidona yodada diluida, cepillado dental y lavado con agua ligeramente ácida, el que era seguido de una nueva aplicación de povidona yodada y aspiración. El protocolo en el grupo control sólo incluía aseo bucal. En el grupo con cuidado oral la incidencia acumulada de NAVM fue significativamente menor $(3,9$ versus $10,4 \%)$, pero no hubo diferencias en otros resultados como estadía en UCI y tiempo de ventilación mecánica.

Clorhexidina: Este agente ha sido ampliamente estudiado y evaluado, tanto en pacientes de UCIs de tipo médica como quirúrgica, y en concentraciones que varían entre 0,12 y $2 \%$. Existe evidencia disponible proveniente de estudios observacionales, estudios randomizados y meta-análisis.

Para el primer tipo de evidencia se cuenta con un estudio observacional ${ }^{35}$ de pacientes ingresados a UCIs de tipo quirúrgica, quemados y con trauma que evaluó el aseo de cavidad oral con pasta de monoflurofosfato $0,7 \%$ para el cepillado, enjuague con agua ácida y aplicación de gluconato de clorhexidina al $0,12 \%$ dos veces al día. Este reporte demostró una reducción relativa de $46 \%$ en la tasa de NAVM. La tasa de adherencia al procedimiento para conseguir estos resultados fue de $81 \%$.

Algunos estudios randomizados no han encontrado un impacto favorable en la reducción en la tasa de NAVM como se reporta en un trabajo ${ }^{36}$ con 512 pacientes ingresados a UCI en el cual evaluó el uso de clorhexidina al 
0,2\% (n: 224 pacientes) versus el uso de una solución de permanganato de potasio (n: 247 pacientes). En este trabajo no se encontraron diferencias en la incidencia de NAVM, la cual fue de 7,1\% en el grupo en estudio versus $7,7 \%$ en el grupo control (p: 0,82). No hubo diferencias en la mediana de días de desarrollo de NAVM, mediana de estadía en UCIs ni mortalidad. Una menor incidencia de NAVM fue descrita durante el período de estudio (7,4 versus $21,7 \%, \mathrm{p}<0,001)$ que en el período previo al estudio (tres meses), probablemente por mayor cuidado en la higiene oral. Esta UCI tenía una población joven y de baja gravedad, y la baja en la incidencia con respecto al período previo plantea un posible efecto Hawthorne.

Se dispone también de un meta-análisis ${ }^{37}$ que seleccionó siete ensayos controlados, randomizados, evaluando en una población total de 1.650 pacientes la eficacia de la clorhexidina tópica en concentraciones de 0,12 a $0,2 \%$ aplicada en oro-faringe versus placebo o cuidado estándar para prevenir la NAVM. Este meta-análisis, evaluó además el subgrupo de pacientes sometidos a cirugía cardiotorácica (443 pacientes asignados a clorhexidina y 471 controles). En los estudios incorporados al meta-análisis, la intervención era iniciada previamente a la intubación y continuada hasta extubación, salida de UCI o muerte. De los cinco estudios más grandes, dos eran doble ciego y analizados con intención de tratamiento. La reducción relativa de NAVM fue de 26\% (p: 0,02). De los siete ensayos, en dos no se demostró disminución de la NAVM, pero de los cinco que demostraron disminución, en dos esta diferencia alcanzó significación estadística. Se demostró presencia de heterogeneidad entre los estudios, de la cual no se determinó la causa. Hubo cinco estudios en que se evaluó la colonización, ya fuese en saliva, placa dental o endotraqueal, sin encontrar diferencias significativas, excepto en un estudio que midió colonización endotraqueal en el grupo tratado, encontrando menos colonización en este grupo. En el análisis por subgrupo, al comparar los pacientes sometidos a cirugía cardio-torácica, en relación a los de UCI general, se demostró un mayor beneficio en los pacientes cardio-quirúrgicos, llegando la disminución del riesgo relativo a $59 \%$.

A pesar de que este meta-análisis demostró una disminución de la frecuencia de NAVM, no se encontró una disminución en la mortalidad, ni en la estadía hospitalaria o de UCI, ni en la duración de ventilación mecánica o en la tasa de reintubación. Los efectos colaterales (sequedad de boca, coloración dental o sabor desagradable) no fueron evaluados. Se concluyó que la solución tópica con clorhexidina disminuye la frecuencia de NAVM, quedando pendientes temas como el evaluar el efecto en mortalidad en estudios más grandes, la costo-efectividad de esta intervención y las reacciones adversas asociadas.

Otra publicación posterior constituye un trabajo controlado, randomizado y no doble ciego ${ }^{38}$. La parte correspondiente al estudio, evaluó la efectividad de la solución de clorhexidina en la prevención de NAVM y la colonización oro-faríngea al realizar un procedimiento de descontaminación oral con $15 \mathrm{ml}$ de clorhexidina al $2 \%$ versus un aseo con solución salina. Ambas intervenciones fueron realizadas cuatro veces al día, con posterioridad al cepillado dental, y aspiración de secreciones en pacientes sobre 18 años en ventilación mecánica en UCI y en salas generales. La colonización fue medida en forma basal y cada siete días hasta la extubación. Un total de 102 pacientes fueron incluidos en el grupo con clorhexidina y 105 en el grupo de solución salina, demostrándose una reducción en la tasa de NAVM de 21 a 7 por 1.000 días de ventilación mecánica (p: 0,04). Este estudio evaluó la irritación de la mucosa oral siendo de $9,8 \%$ para el grupo de clorhexidina y $0,9 \%$ para el comparador (p: 0,001). La colonización por bacilos gramnegativos durante el tratamiento fue menor en el grupo de clorhexidina y los recuentos bacterianos tendían a disminuir en este mismo grupo. La mortalidad en este estudio fue similar (32,3\% en el grupo clorhexidina y $35,2 \%$ en el comparador) y tampoco hubo diferencias en la duración de la ventilación mecánica, o la estadía en UCI. En este estudio, esta medida se mostró costo-efectiva con un costo de 34 dólares para prevenir un cuadro de neumonía (el costo del la solución fue estimado en 40 centavos de dólar al día).

El meta-análisis incluido en la referencia 37 y citado más arriba comparó sus propios resultados contra los provenientes de otros tres meta-análisis. El meta-análisis del estudio, incluyo sólo dos trabajos: el comentado y el único que usaba la misma concentración de clorhexidina (2\%). Los resultados mostraron que existía una reducción relativa de la NAVM de $47 \%$ (p: 0,02), concluyéndose que se requería tratar a 14 pacientes para prevenir un cuadro de NAVM.

Finalmente, otra revisión sistemática y meta-análisis ${ }^{39}$ incluyó ensayos controlados en pacientes adultos en ventilación mecánica y comparó los efectos de la aplicación diaria de antimicrobianos o antisépticos versus ninguna profilaxis, incorporando siete estudios con un total de 2.144 pacientes para el análisis del uso de antisépticos orales (1.066 en el grupo con antisépticos y 1.078 en el grupo control). Los resultados mostraron que el uso oral de antisépticos redujo la incidencia de NAVM, con una reducción del riesgo relativo de 44\% (p: 0,02). Se requeriría tratar 14 pacientes para evitar un episodio de NAVM. En esta revisión tampoco se demostró una disminución de la mortalidad, de la duración de la ventilación mecánica o de la estadía en UCIs. La discusión sobre la antibioterapia tópica se encuentra en la sección precedente de este consenso, por lo que no se comenta en esta sección en referencia al estudio citado.

Los datos presentados permiten recomendar la implementación del aseo de la cavidad oral con clorhexidina, 
por ser eficaz en la disminución en la incidencia de NAVM; y aparentemente ser costo-efectiva (IB). Las ventajas de esta práctica serían mayores en la población cardio-quirúrgica. La concentración ideal a recomendar no puede ser establecida (IIIC), no obstante, la buena efectividad de las soluciones al $2 \%$, con pocas reacciones adversas significativas, sugiere que podría ser ésta la mejor concentración (IIIC).

La profilaxis con iseganan no se recomienda (IIE).

\section{¿Tiene relevancia el control de la presión del cuff en el riesgo de NAVM?}

La región sobre el cuff es un lecho donde frecuentemente se produce acumulación de secreciones permitiendo el desarrollo de microorganismos; se ha señalado que los momentos en que baja la presión del cuff constituirían eventos que facilitan la colonización de la vía aérea inferior. Existe una publicación ${ }^{40}$ que analizó la utilidad del uso de un dispositivo para mantener la presión del cuff entre 20 y $30 \mathrm{~cm}$ de $\mathrm{H}_{2} \mathrm{O}$ comparado con el cuidado corriente de la presión del cuff para evitar el paso de secreciones a la vía aérea inferior. Los resultados de este trabajo, realizado en una población de 142 pacientes mostraron que había menos episodios de presión del cuff bajo $20 \mathrm{~cm} \mathrm{H}_{2} \mathrm{O}$ en el grupo que incorporó este dispositivo pero no hubo diferencias en la incidencia de NAVM, ni en la mortalidad, ni en ninguno de los otros análisis realizados en el estudio. Así, el uso de dispositivos para mantención continua de la presión del cuff no está recomendado (IE). En nuestro consenso, basado en opinión de expertos, se recomienda la medición rutinaria de la presión del cuff, pero no hay argumentos para la medición continua de la presión (IIIB).

\section{¿Qué vía de intubación es más segura para prevenir la NAVM?}

Con la intubación oro-traqueal pueden arrastrarse microorganismos presentes en la oro-farinx hacia la tráquea. La intubación naso-traqueal no está exenta de esta situación, más aún, ésta se asocia a mayor incidencia de sinusitis ${ }^{41,42}$ y ésta a su vez podría aumentar el riesgo de $\mathrm{NAVM}^{41,43}$. Un estudio controlado con un grupo de pacientes intubado por vía naso-traqueal y otro por vía oro-traqueal encontró en el análisis multivariado que la sinusitis es un factor que aumenta en 3,8 veces la frecuencia de $\mathrm{NAVM}^{42}$. En otro ensayo controlado ${ }^{41}$ realizado en pacientes con intubación naso-traqueal se comparó la incidencia de NAVM en dos grupos. En el primero de ellos se realizó la búsqueda sistemática de sinusitis maxilar con tomografía axial computada al $4^{\circ}$ y $7^{\circ}$ día de intubación y en caso de haber signos de sinusitis se procedía a iniciar tratamiento antimicrobiano. En el segundo grupo (control) no se hizo búsqueda activa de sinusitis. Se encontró una menor incidencia significativa de NAVM en el grupo con búsqueda activa (34 versus 47\%, $\mathrm{p}=0,02$ RR 0,61 IC 95 $0,4-0,93)$. Este último hallazgo apoya que la presencia de infección en la cavidad nasal es un factor importante en la patogenia de la NAVM en el paciente con intubación naso-traqueal.

Este consenso estima que la vía de intubación orotraqueal debe preferirse a la naso-traqueal. (IA). La búsqueda activa de sinusitis por tomografía axial computada debe considerarse en los pacientes con intubación naso-traqueal (IIB).

\section{¿Existe un rol para el uso de los tubos oro-traqueales impregnados?}

En la última década se ha incorporado a la práctica clínica los tubos oro-traqueales impregnados con plata. Inicialmente probados en un estudio en animales, posteriormente se realizó un estudio controlado, randomizado ${ }^{44}$, que demostró una disminución en la incidencia de NAVM de 7,5 a 4,8\% en los pacientes intubados por un tiempo igual o mayor a 24 horas (p: 0,03). A pesar de los hallazgos en este estudio, el costo de ellos podría representar una limitante a su implementación. Además, no se ha repetido aún el resultado obtenido en este estudio. Por tanto, se recomienda su implementación sólo si su costo es razonable ya que hay medidas de mayor beneficio y menor costo que deben intentarse antes (IIB).

\section{La incorporación de la técnica de aspiración subglótica ¿es eficaz para prevenir la NAVM?}

La aspiración sub-glótica es una técnica que se ha planteado como efectiva en disminuir la NAVM. El raciocinio de este planteamiento es que las secreciones acumuladas sobre el cuff permiten la proliferación de las bacterias que posteriormente pasan a la vía respiratoria inferior para ocasionar la NAVM. Para aspirar estas secreciones se han utilizados tanto sondas aisladas como tubos endotraqueales con accesorios que permiten la aspiración de secreciones. Se ha discutido en modelos in vitro que la reducción de la carga bacteriana en las vías aéreas inferiores sería mínimamente alterada por estos tubos; no obstante, los resultados clínicos han sido satisfactorios.

Este tema ha sido analizado en un meta-análisis ${ }^{45}$, que revisó 110 estudios, de los cuales cinco cumplieron los criterios de inclusión con un enrolamiento de 896 pacientes. Los resultados demostraron que esta técnica disminuiría prácticamente a la mitad la incidencia de NAVM (RR $0,51)$, reduciendo principalmente la neumonía precoz (entre el $5^{\circ}$ y $7^{\circ}$ día después de la intubación). En cuatro estudios analizados - uno se debió retirar por heterogeneidad para este análisis- la duración de la ventilación mecánica disminuyó en promedio dos días con el uso de esta técnica y la estadía en UCIs se redujo en tres días.

Este consenso recomienda la implementación de las técnicas de aspiración subglótica (IA). El uso de los tubos 
endotraqueales especialmente diseñados para este fin parece razonable dada la pequeña diferencia de precio con los tubos endotraqueales de uso habitual.

\section{El irrigar con solución salina (“suero fisiológico”) un sistema cerrado previo a la aspiración ¿puede ayudar en la prevención de la NAVM?}

Caruso P. y cols, propuso la instilación de $8 \mathrm{~mL}$ de solución salina estéril previo a la aspiración de los sistemas cerrados como una medida de disminución de la incidencia de $\mathrm{NAVM}^{46}$. El estudio randomizó 130 pacientes a instilación de solución salina y a 132 sin ninguna intervención de este tipo. Esto disminuyó significativamente la incidencia de NAVM de 15,4 en el grupo control a 9,62 por 1.000 días de ventilación mecánica en el grupo con instilación de solución salina. La NAVM demostrada microbiológicamente fue de $23,5 \%$ en el grupo control versus $10,8 \%$ en el grupo con intervención $(\mathrm{p}=0,008)$. No obstante, no hubo diferencias en el uso de antimicrobianos por paciente, en la estadía en UCI, ni en mortalidad. En vista de lo potencialmente beneficiosa y simple de implementar, este consenso considera que esta técnica puede ser utilizada en las unidades que deseen implementarlo (IIC), pero estos datos deberán ser reproducidos a futuro para mantener la recomendación.

\section{Los sistemas de aspiración de secreciones en forma abierta o cerrada ¿tienen incidencia en la tasa de NAVM?}

Este tema ha sido estudiado en varios trabajos $\operatorname{controlados}^{47,48}$, incluyendo su costo y consecuencias psicológicas $^{48,49}$. Los datos atingentes a neumonía han sido resumidos en un meta-análisis ${ }^{50}$ que evaluó en 1.272 pacientes la efectividad del sistema de aspiración cerrado versus abierto y su efecto sobre la NAVM, no encontrando una diferencia significativa $\left(\mathrm{RR} 0,96 ; \mathrm{IC}_{95} 0,76-1,21 ; \mathrm{p}=\right.$ $0,39)$. Tampoco hubo diferencia en la mortalidad en UCI en 1.062 pacientes. En dos ensayos controlados de este meta-análisis, se evaluó el costo del procedimiento, el que fue superior en el sistema cerrado. Un meta-análisis realizado en neonatos ${ }^{51}$ no logró ser concluyente debido a que sólo incorporó 22 pacientes.

Entre las ventajas del uso del sistema cerrado de aspiración estaría el estar asociado a una menor cantidad de episodios de hipoxia y arritmias; sin embargo, no habiendo diferencia respecto a la incidencia de NAVM ni mortalidad, se debe considerar que no hay diferencias importantes entre ambos sistemas ${ }^{47,49,50}$. Desde el punto de vista funcional, el sistema cerrado permite que al no desconectar el ventilador durante la aspiración, los pacientes que reciben una presión de final de espiración elevada (PEEP) no pierden este aporte durante la aspiración. A su vez, reducen el riesgo de exposición del personal de salud a aerosoles. Se ha mencionado como una desventaja potencial de los sistemas cerrados, una mayor colonización por $P$. aeruginosa, pero sin mayor incidencia de neumonía ${ }^{48}$. Por otra parte, el sistema cerrado tiene la ventaja que se requiere sólo una persona para realizar el procedimiento, a diferencias de las dos que se requieren para la aspiración con el sistema abierto. Este consenso estima que no existen argumentos para la aplicación de uno u otro sistema por lo que en la elección de cada unidad se debe priorizar los costos de cada uno de ellos, siendo en la mayoría de los casos superior el costo del sistema cerrado (IC). En el caso de pacientes que presentan patología infecciosa con riesgo de contagio al personal de salud (por ejemplo tuberculosis o hantavirosis), o que se estén manejando con altos niveles de PEEP, es razonable preferir el manejo con sistemas cerrados de aspiración, aunque no hay evidencias importantes en la literatura científica que permitan fundamentar este punto (IIIB).

Se ha comparado además el cambio del sistema cerrado cada 24 horas versus el no cambio rutinario, esto es, cambiar cuando sea necesario, o hasta un máximo de una semana. Sin embargo, no se ha demostrado diferencia entre ambas estrategias ${ }^{52}$. Este consenso estima que, dado que no hay elementos para beneficiar el cambio diario del sistema cerrado de aspiración, no se sugiere el cambio rutinario de estos dispositivos (IIIC).

\section{¿Es de utilidad la higiene de manos previa a la aspiración de secreciones en la prevención de la NAVM?}

El beneficio de los distintos procedimientos de higiene de manos no ha sido probado fehacientemente en trabajos controlados, randomizados, que evalúen su impacto en la prevención de la NAVM. Actualmente, a pesar de esta falta de datos, la gran mayoría de las guías y revisiones recomienda su implementación, puesto que el uso de las medidas estándares ha tenido un impacto en la disminución global de las infecciones asociadas a la atención de salud, lo que es extrapolado a la NAVM. Los problemas éticos que implicaría el diseño de un estudio que limite una medida demostrada en el manejo general de los pacientes en cuidados intensivos ${ }^{53,54,55}$ hacen imposible la realización de un estudio que evalúe cuáles medidas son las más efectivas en la prevención de la NAVM. Asimismo, también se recomiendan las medidas de precauciones de contacto utilizadas para prevenir la transmisión cruzada de infecciones por microorganismos multi-resistentes ${ }^{55}$.

Este consenso, considera esencial la práctica de las medidas de higiene estándares para la prevención de la NAVM (IIA).

\section{¿Cuál es la utilidad de los filtros bacterianos en la prevención de la NAVM?}

La utilización rutinaria de filtros bacterianos ha sido recomendada desde muchos años en forma empírica, prác- 
ticamente como una norma de seguridad de la ventilación mecánica y su uso ha sido recomendado en forma rutinaria sin un apoyo bibliográfico importante ${ }^{56}$.

No obstante, un trabajo controlado, randomizado, analizó este punto en forma específica, en una población de 230 pacientes en ventilación mecánica por sobre $24 \mathrm{hrs}$. Se comparó el uso de filtro bacteriano en los circuitos del ventilador mecánico en 114 pacientes con 1.665 días de ventilación mecánica versus no uso de filtro bacteriano en 116 pacientes con 1.722 días de ventilación mecánica no encontrando diferencias, ya fuese en la tasa de NAVM por 1.000 días de ventilación mecánica $(2,4$ vs $1,74 \%$ ), en otras infecciones respiratorias asociadas a ventilación mecánica, en eventos infecciosos exógenos o en la mortalidad ${ }^{57}$.

Si bien, los resultados de este trabajo son un gran aporte en este tópico, la aplicación a la realidad chilena no es totalmente extrapolable dadas las tasas muy bajas de NAVM reportadas en ambos grupos, respecto a lo observado en nuestro país. Por tanto, este consenso considera que no hay suficiente evidencia para recomendar o rechazar su uso (IIIC).

\section{¿Con qué frecuencia se deben cambiar los circuitos del ventilador mecánico para prevenir la NAVM?}

El consenso anterior recomendó el cambio semanal de circuitos, basado mayoritariamente en trabajos que usaron como comparador el cambio rutinario cada 48 horas $^{16}$. Se han sumado desde entonces dos trabajos que evaluaron una estrategia consistente en la instalación de circuitos nuevos al ingresar el paciente a ventilación mecánica para posteriormente no cambiarlos durante el tiempo que dure la ventilación mecánica, a menos que se produzca un daño o una contaminación evidente de éstos. En uno de estos trabajos la incidencia de NAVM fue de $24,5 \%$ para el grupo sin cambio de circuitos versus $28,8 \%{ }^{58}$ para el de cambio semanal de circuitos. Las tasas en el otro trabajo fueron de $23,0 \%$ para el grupo sin cambio de circuitos versus $23,1 \%$ para el grupo con cambio de circuitos cada 48 horas $^{59}$. Como se puede apreciar, no hubo en estos estudios diferencias en la incidencia de NAVM ni en mortalidad, lo que concuerda con los resultados históricos. Variaciones de estas estrategias han sido mencionadas en otros estudios y con otras metodologías ${ }^{60}$. Las estrategias de cambio cada dos días, cada siete días o no cambio de circuitos han sido recientemente comparadas en un meta-análisis que incluyó varios trabajos controlados, randomizados, pero también estudios secuenciales en que se cambiaba de una práctica a la otra ${ }^{61}$. Este meta-análisis consideró en su análisis la comparación de dos o tres días para cambios de circuitos versus cambios cada siete días y se excluyó un estudio que había incluido pacientes de muy baja gravedad (no eran todos pacientes con criterios de paciente crítico y tenían una tasa de neumonía menor de $3 \%$ ), y se pudo concluir, en base a estudios secuenciales, que el cambio más frecuente estaba asociado a un mayor riesgo de desarrollar neumonía, OR 1,9 (95\% CI 1,080-3,44), siendo, por tanto, menos riesgoso el cambio menos frecuente de circuitos. En el segundo análisis del estudio se comparó el no realizar cambio rutinario de circuitos versus un cambio periódico de ellos, incluyendo tres ensayos controlados. No se encontraron diferencias en el riesgo de desarrollar NAVM entre la estrategia con cambio cada dos o siete días versus el no cambio de los circuitos (OR 1,1; 95\% CI 0,793-1,599), sin encontrarse heterogeneidad en el análisis. Un tercer resultado dentro de esta revisión sistemática apunta a la consistencia de los datos. De esta manera, se observó una relación lineal entre el riesgo de desarrollar NAVM y los cambios cada vez más frecuentes del ventilador mecánico.

En vista de estos resultados, la recomendación del consenso es no realizar cambio programado de circuitos y cambiarlo sólo en caso de detectar daño o contaminación evidente de los circuitos (IA).

\section{¿Qué tipo de humidificador es mejor en la prevención de NAVM?}

Los métodos de humidificación en ventilación mecánica se realizan por humidificadores higroscópicos, o bien, por humidificadores tipo cascada. Estos últimos requieren dispositivos adosados al ventilador mecánico y generan gran cantidad de líquido condensado en las mangueras del ventilador mecánico que deben ser evacuadas periódicamente por el personal de enfermería y donde cada proceso de conexión-desconexión facilita la contaminación de ellos y la potencial entrada de un inóculo por vía endoluminal al paciente. La comparación de ambos tipos de humidificación y la incidencia de NAVM relacionada a cada dispositivo ha sido el objetivo de diversos ensayos clínicos que han generado varios metaanálisis subsiguientes. La conclusión de los autores de los dos primeros meta-análisis es que el uso de los humidificadores higroscópicos produciría una disminución en la incidencia de NAVM ${ }^{62,63}$. Debe considerarse, no obstante, que el segundo estudio ${ }^{63}$ fue muy selectivo en la calidad de los estudios incluyendo sólo dos trabajos controlados. La revisión sistemática actualizada recientemente por la colaboración Cochrane ${ }^{64}$, incluyó un total de 33 estudios (13 estudios eran de origen francés), de los cuales sólo tres eran en población pediátrica. El total de pacientes incluidos fue de 2.833 participantes. Este trabajo concluyó que, tanto la oclusión de vía aérea como la incidencia de neumonía (RR 0,92; $\mathrm{IC}_{95} 0,71$ a 1,20 en 2.236 pacientes), complicaciones respiratorias y mortalidad (RR 1,04; $\mathrm{IC}_{95} 0,90$ a 1,21 en 1.951 pacientes), eran similares en ambos grupos. No obstante, algunos resultados mostraron algunas diferencias en otros aspectos, destacando datos que apuntaban a que los humidificadores higroscópicos 
de tipo hidrofóbico podrían tener una menor incidencia de NAVM (RR 0,47; IC $_{95} 0,27$ a 0,81) No obstante, no se consideró este resultado como evidencia definitiva ya que correspondía a una conclusión derivada de sólo tres estudios. Una desventaja potencial de los humidificadores higroscópicos sería que algunos subgrupos de pacientes, como los que tienen abundantes secreciones, podrían tener una mayor obstrucción de la vía aérea.

En vista a los resultados señalados, este consenso considera que el uso de humidificadores higroscópicos es equivalente al uso de humidificadores de cascada desde el punto de vista del riesgo de NAVM (IA). Las consideraciones del uso de uno u otro quedan sujetas a criterio de la medicina intensiva, incluyendo la liberación potencial de horas de trabajo del personal de enfermería que podría dedicarse a otras medidas asistenciales o preventivas. Queda pendiente a futuro la posibilidad que nuevos datos confirmen la posibilidad que los humidificadores hidrofóbicos tengan un menor riesgo de NAVM (IIC).

\section{¿Con qué frecuencia se deben cambiar los humidificadores higroscópicos para prevenir la NAVM?}

Los humidificadores higroscópicos deben cambiarse en forma rutinaria según las recomendaciones de los fabricantes pero en la última década se han realizado dos investigaciones analizando este aspecto en forma más detallada. En el primero de éstos ${ }^{65}$ se estudiaron 220 pacientes sometidos a ventilación mecánica por más de 48 horas, separados en tres grupos: uno con cambio diario del humidificador higroscópico y en los otros dos grupos el cambio se hacía después de 120 horas (cinco días), en un caso utilizando el mismo humidificador higroscópico y en el otro utilizando un humidificador hidrofóbico. No se demostraron diferencias en la eficiencia de los dispositivos para reducir la incidencia de NAVM ni en la cuantificación de la colonización bacteriana del dispositivo en el lado del paciente. La incidencia de neumonía no fue diferente $(8,0 \%, 6,6$ y $8,3 \%$ respectivamente). Debe destacarse que el promedio de uso del dispositivo en los grupos de uso prolongado fue de 73 y 74 horas (cerca de tres días), a pesar de haberse planificado por 120 horas (cinco días); por esto debe considerarse que con frecuencia estos dispositivos serán probablemente cambiados antes de este plazo. El segundo estudio ${ }^{66}$ comparó el uso de un humidificador de tipo hidrofóbico en dos grupos: uno asignado a cambio diario del dispositivo y el otro a un cambio semanal, incorporando 155 pacientes con ventilación mecánica por más de 48 horas. La incidencia de NAVM fue de $24 \%$ en el grupo con cambio diario y $17 \%$ en el de cambio semanal, no siendo estas diferencias significativas. En vista de la equivalencia demostrada entre ambas estrategias, no existiendo además tendencia alguna hacia daño y tratándose además de una estrategia costo-efectiva, este consenso recomienda el cambio del humidificador higroscópico cada cinco a siete días (IIB).

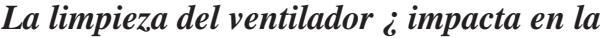 frecuencia de NAVM?}

Las técnicas de esterilización y desinfección datan en la medicina desde principios del siglo XX y su uso masivo ya desde los años '40, o sea, con bastante antelación al inicio de la ventilación mecánica moderna. Al empezar los procedimientos de ventilación mecánica, estas técnicas se incorporaron a esta nueva técnica. Así, los datos que aportan la utilización de estas técnicas no vienen de trabajos controlados, randomizados, sino de estudios que muestran que la esterilización de las piezas del ventilador es efectiva en la eliminación de la contaminación bacteriana ${ }^{67}$. Por otro lado, existen múltiples reportes de brotes asociados a contaminación, tanto de los circuitos como las bolsas de ventilación ${ }^{68,69}$. Se ha propuesto que la utilización de filtros bacterianos permitiría obviar los pasos de esterilización de la vía respiratoria del ventilador; sin embargo, este punto es muy controvertido en la literatura médica, sin trabajos clínicos que lo avalen $\left({ }^{67}\right)$. Se ha reportado también, que la presencia de material orgánico en las fisuras del material reutilizable, que haya sido empleado por largo tiempo, es difícil de eliminar y facilita la persistencia de los microorganismos en forma posterior a los procedimientos habituales de esterilización o desinfección ${ }^{70}$.

Este consenso recomienda la limpieza de la parte interna del ventilador y no realizar procedimientos de desinfección de alto nivel (DAN) o esterilización de dicha parte (III A). Situación similar a la mayoría de las guías internacionales.

\section{La incorporación de técnicas de kinesioterapia ¿logra disminuir la frecuencia de NAVM?}

El uso de la kinesioterapia en la prevención de la NAVM ha sido pobremente estudiado. El análisis de un trabajo del uso de terapia kinésica en pacientes neurológicos no muestra eficacia en la prevención de neumonía, ni en la estadía en la UCI, ni en los días de ventilación mecánica. Este estudio incluyó sólo 144 pacientes, de los cuales 33 (19,4\% en el grupo con fisioterapia y $26,4 \%$ en el control, p: 0,32) desarrollaron NAVM. El pequeño número de pacientes incluidos no permite descartar completamente la posibilidad de un beneficio ${ }^{71}$. Otro trabajo, pero realizado en una población de 236 pacientes post-operados de cirugía cardíaca electiva o semi-electiva, tampoco mostró beneficio de la kinesioterapia durante el período que el paciente permanecía intubado, el cual fue en promedio menos de 13 horas $^{72}$. Finalmente, un trabajo ${ }^{73}$ realizado en un centro en India con 101 pacientes que fueron randomizados a recibir vibraciones torácicas durante su kinesioterapia, recibiendo todos hiperinflación manual con 
bolsa de ventilación y aspiración de secreciones durante las sesiones, mostró una disminución estadísticamente significativa en el CPIS (Clinical Pulmonary infection Score) que era el resultado principal, pero no hubo diferencias en la frecuencia de NAVM. La mortalidad fue mucho mayor en el grupo control (49 versus $24 \%$ ), pero no se menciona en el estudio explicación alguna posible de este fenómeno.

Los resultados señalan que la fisioterapia no ha mostrado ser dañina para los pacientes en ventilación mecánica. Dado que no está demostrada su eficacia este consenso no recomienda ni desalienta su uso (IIIC).

\section{La ventilación mecánica no invasora ¿̇logra disminuir la frecuencia de NAVM?}

La ventilación mecánica no invasora se ha utilizado mayoritariamente como una opción previa a las ventilación mecánica o en el tratamiento del edema pulmonar agudo $^{74}$. No obstante, en las últimas décadas se han publicado varios trabajos buscando apoyar el éxito del weaning (desconexión) de la ventilación mecánica no invasora, siendo los resultados de éstos, polémicos y contradictorios. En varios de estos estudios se ha medido además la posibilidad que esta intervención disminuya la frecuencia de la NAVM en forma posterior al weaning. Este tema ha sido también ampliamente discutido en la literatura científica ${ }^{75}$, a pesar de la existencia de un meta-análisis reciente ${ }^{76}$. En este último, se incluyeron 12 trabajos (530 pacientes), de los cuales ocho enrolaron pacientes con enfermedad pulmonar obstructiva crónica y cuatro con una población mixta. Si bien el meta-análisis fue considerado como positivo por los autores demostrando una disminución de la frecuencia de NAVM $(0,29$; IC $0,19$ a 0,45$)$ y de mortalidad (RR 0,55 ; IC 0,38 a 0,79 ), su revisión demuestra que este resultado es generado por los resultados de los trabajos hechos en pacientes con enfermedad pulmonar obstructiva crónica donde el RR de mortalidad es 0,42 (IC $(0,25$ a 0,69$)$ más que por los efectuados en la población mixta (RR 0,72; 0,39 a 1,32).

Basados en estos resultados, se recomienda considerar la realización del weaning de la ventilación mecánica invasora con ventilación mecánica no invasora en pacientes con antecedentes de enfermedad pulmonar obstructiva crónica (IIB) como una forma de prevención de la NAVM. No obstante, en vista de las otras variables a evaluar en el proceso del weaning se hace énfasis en revisar esta indicación caso a caso, según la opinión del médico intensivista.

\section{La ventilación por traqueostomía ¿cambia la incidencia de NAVM?}

La traqueostomía es un procedimiento relativamente frecuente en UCI y que ha sido facilitado por la incorporación de la técnica percutánea. Entre los varios beneficios potenciales de la traqueostomía se ha mencionado un mayor confort del paciente, menos requerimiento de sedación, períodos de weaning más breves y una menor incidencia de $\mathrm{NAVM}^{75}$, por lo que varios grupos han sugerido la realización precoz de esta intervención. Por otro lado, varios de estos posibles beneficios han sido estudiados con resultados no tan consistentes. Existe un meta-análisis ${ }^{77}$ que ha evaluado si la realización precoz (antes de siete días desde el inicio de la ventilación mecánica invasora) de la traqueostomía mejora los resultados de los pacientes sometidos a este procedimiento. Este estudio consideró cinco investigaciones con un total de 406 pacientes, mostrando un RR de 0,90 de presentar NAVM (IC 0,66 a 1,21), lo que no es significativo; no obstante, se encontraron beneficios en la duración de la ventilación mecánica y en la duración de la estadía en la UCI.

Estos antecedentes indican que la realización precoz de la traqueostomía no ha demostrado disminuir la incidencia de NAVM, por lo que no debe ser recomendada con esta indicación específica (IC). No obstante, existen otros resultados que podrían ser ventajosos para los médicos que trabajan en cuidados intensivos, como el acortamiento de los días de ventilación mecánica, que pueden llevar a su indicación en la práctica habitual y que se encuentran fuera de los alcances de este consenso.

\section{La remoción de secreciones orales previo a los cambios de posición ¿disminuye la incidencia de NAVM?}

Esta práctica, frecuente en muchas unidades clínicas, ha sido pobremente evaluada respecto a su efectividad para prevenir la NAVM. La única referencia ${ }^{78}$ corresponde a un estudio secuencial (cuatro meses de práctica habitual, luego dos meses de entrenamientos y luego cuatro meses de evaluación), realizado en la ciudad de Taipei, Taiwan. La aspiración se realizaba antes de cada cambio de posición del paciente introduciendo una sonda de aspiración en la boca y manteniéndolo durante 10 segundos con una presión negativa de 60 a 80 mmHg. En el grupo control (159 pacientes) se presentaron 24 casos de NAVM $(15,1 \%)$, mientras que en el grupo experimental (102 pacientes) se produjeron cinco episodios de NAVM $(4,9 \%)$, lo cual constituyó una disminución con un RR de 0,32 (IC 0,11 a $0,92)$. No obstante, el diseño del estudio es una limitación importante, así como que haya sido realizado en un solo centro. Asimismo, llama la atención que habiendo sido períodos similares de inclusión de pacientes, se haya enrolado muchos más pacientes durante el período control (159 pacientes) que en el experimental (102 pacientes).

Este consenso concluye que puede considerarse la adopción de la aspiración de secreciones orales previo a los cambios de posición del paciente ya que constituye una intervención simple y no dañina, dependiendo de la decisión de cada unidad clínica (IIIB). 


\section{El uso de probióticos ¿disminuye la frecuencia de NAVM?}

El uso de probióticos tiene por objeto cambiar la microbiota del tracto digestivo por agentes biológicos menos virulentos, que disminuyan la posibilidad de que microorganismos patógenos alcancen el tracto respiratorio. Ocho trabajos controlados, randomizados, han evaluado este punto y un meta-análisis de buena metodología, publicado recientemente, consideró cinco de éstos como aceptables para incluirlo en su análisis ${ }^{79}$. En estos estudios se utilizaron distintos compuestos de probióticos incluyendo diferentes microorganismos. Las especies que han sido consideradas a utilizar en, al menos, uno de los compuestos son Pediococcus pentosaceus, Leuconostoc mesenteroides, Lactobacillus paracasei subspecies paracasei, Lactobacillus plantarum, Lactobacillus casei, Lactobacillus rhamnosum y Lactococcus raffinolactis. El meta-análisis con 645 pacientes mostró una disminución significativa de la frecuencia de NAVM con un OR de 0,61 (IC 0,41 a 0,91). Tres de los estudios utilizaron una solución de probióticos casi equivalente; dos de ellos habían alcanzado una reducción estadísticamente significativa de la frecuencia de NAVM. El análisis de estos tres estudios (437 pacientes), también demostró una disminución significativa de la NAVM (OR 0,44; IC $0,25$ a 0,75$)$. Sin embargo, no hubo diferencias de duración en la ventilación mecánica, mortalidad intrahospitalaria ni mortalidad global.

De los datos señalados y la consideración de la homogeneidad de las distintas soluciones de probióticos, se concluye que los probióticos pueden ser considerados como una estrategia de prevención de la NAVM, lo cual debe ser evaluado por cada unidad clínica, dado el peso de la evidencia actual (IIC).

\section{Las nebulizaciones con antimicrobianos ¿pueden servir como profilaxis de la NAVM?}

Las nebulizaciones de antimicrobianos corresponden a una intervención que se ha utilizado en distintos escenarios clínicos de la NAVM y mediante diferentes tipos de dispositivos para su aplicación. La mayoría de sus aplicaciones han sido relacionadas a terapia, habiendo mucha menor información respecto a profilaxis ${ }^{80}$. Los trabajos iniciales para esta intervención (utilizando polimixina $\mathrm{B}$ en faringe y tubo endotraqueal) mostraron en una serie controlada, en que no todos los pacientes se encontraban en ventilación mecánica, una disminución de la colonización por $P$. aeruginosa ${ }^{81}$, por lo que posteriormente el mismo grupo realizó un estudio no controlado que mostró baja incidencia de neumonía por este microorganismo, pero aumento de la neumonía por bacilos gramnegativos resistentes a polimixina $\mathrm{B}$, con una alta mortalidad asociada ${ }^{82}$. Otro estudio similar, en
744 pacientes utilizando polimixina B en aerosol en pacientes no necesariamente en ventilación mecánica, pero usando ciclos de dos meses para enrolar pacientes que se asignaban a control o placebo, demostró disminución de la colonización por $P$. aeruginosa, pero sin cambios en la mortalidad ${ }^{83}$; asimismo, hubo una tendencia a la disminución en la neumonía nosocomial por este agente. Este estudio tiene varios problemas metodológicos como que 52 pacientes tuvieron períodos con y sin polimixina a la vez. Un estudio citado habitualmente como de profi-

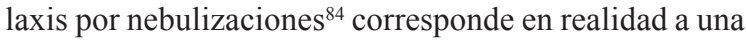
administración profunda de soluciones de gentamicina a través del tubo endotraqueal. Este estudio también tiene limitaciones metodológicas ya que, a pesar de ser doble ciego, se retiraron varios pacientes del análisis ya que tenían infección al inicio del estudio. En los resultados menciona una disminución de las infecciones bajas, pero esto lo hace en base a una menor obtención de secreciones purulentas en los aspirados y en los resultados de microbiología obtenidos por el tubo endotraqueal, lo que podría haber estado alterado por la administración del antimicrobiano, mientras por otra parte señala que no había diferencias en las imágenes de radiografía de tórax entre ambos grupos. Al respecto, un trabajo prospectivo, randomizado, que usó posteriormente esta intervención, no pudo demostrar disminución de la frecuencia de neumonía o en la mortalidad ${ }^{85}$. Se pudo identificar además, dos trabajos controlados que utilizaron profilaxis de NAVM con antimicrobianos en aerosol realizados por el mismo grupo de investigación y utilizando ceftazidima. En el primero ${ }^{86}$, que corresponde a una experiencia inicial con 40 pacientes, se mostró una disminución significativa de la NAVM en una UCI $(30 \%$ en grupo tratado versus $65 \%$ en el control (p 0,022$)$. No obstante, en el siguiente trabajo ${ }^{87}$ con 101 pacientes incluidos, el resultado no fue significativo sobre la frecuencia de neumonía a 30 días ( $49 \%$ en el grupo tratado y $50 \%$ en el grupo control). Un meta-análisis ${ }^{88}$ que incluyó el primero de los dos trabajos recién mencionados, el trabajo inicial realizado con polimixina $\mathrm{B}$, los dos en los que se realizó instilación endotraqueal con gentamicina, más un estudio con tobramicina en nebulización que había incluido 69 pacientes mostrando una disminución no significativa en la frecuencia de la $\mathrm{NAVM}^{89}$, llegó a la conclusión que con el uso de profilaxis había un menor riesgo de neumonía ( $\mathrm{OR}=0,49 ; 95 \%$ IC 0,32 a 0,76 ), pero no en la mortalidad (OR $=0,86 ; 95 \%$ IC $0,55-1,32)$.

En vista de los resultados expuestos de los trabajos individuales, la calidad metodológica descrita de la mayoría de ellos, lo cual a nuestro juicio hace dudosos los resultados del meta-análisis, nos permite concluir que no hay evidencia suficiente para recomendar el uso de antimicrobianos por vía respiratoria para profilaxis de NAVM (IID). 
Tabla 2. Medidas no farmacológicas con impacto en la prevención de la NAVM

\begin{tabular}{|lccc|}
\hline Intervención & Estudio & $\begin{array}{c}\text { Impacto en } \\
\text { NAVM }\end{array}$ & IC95 \\
No farmacológicas & Meta-análisis & OR 0,47 & $0,27-0,82$ \\
\hline $\begin{array}{l}\text { Cabecera elevada } 30 \text { a } 45^{\circ} \\
\text { Drenaje subglótico }\end{array}$ & Meta-análisis & RR 0,51 & $0,37-0,71$ \\
$\begin{array}{l}\text { VM no invasora vs VM para weaning de } \\
\text { pacientes con EPOC }\end{array}$ & Meta-análisis & $\begin{array}{c}\text { RR 0,42 } \\
\text { (mortalidad) }\end{array}$ & $0,25-0,69$ \\
\hline $\begin{array}{l}\text { Aspiración bucal antes de cambios de posición } \\
\text { Instilación SF (8 mL) antes de aspiración }\end{array}$ & Antes-después & Rnsayo randomizado 0,32 & $0,11-0,92$ \\
\hline TOT impregnado con plata & Rn 0,54 & $0,18-0,74$ \\
\hline $\begin{array}{l}\text { OR: odds ratio. RR: riesgo relativo. RRR: reducción de riesgo relativo. TOT: tubo oro-traqueal. Refe- } \\
\text { rencias en el texto. }\end{array}$ & & \\
\hline
\end{tabular}

Tabla 3. Medidas farmacológicas con impacto en la prevención de la NAVM

\begin{tabular}{|c|c|c|c|}
\hline Intervención & Estudio & Impacto en NAVM & IC95 \\
\hline Higiene bucal con clorhexidina & Meta-análisis & RR 0,74 & $0,56-0,96$ \\
\hline $\begin{array}{l}\text { Profilaxis antimicrobiana tópica } \\
\text { (no inhalatoria) + sistémica }\end{array}$ & Meta-análisis & RR 0,28 & $0,20-0,38$ \\
\hline $\begin{array}{l}\text { Profilaxis antimicrobiana tópica } \\
\text { (no inhalatoria) }\end{array}$ & Meta-análisis & RR 0,34 & $0,21-0,55$ \\
\hline Profilaxis antimicrobiana inhalatoria & Meta-análisis & RR 0,49 & $0,32-0,76$ \\
\hline $\begin{array}{l}\text { Descontaminación selectiva del tracto } \\
\text { intestinal en pacientes quirúrgicos }\end{array}$ & Meta-análisis & $\begin{array}{c}\text { RR 0,19 } \\
\text { (todo tipo de neumonía) }\end{array}$ & $0,15-0,26$ \\
\hline $\begin{array}{l}\text { Descontaminación selectiva del tracto } \\
\text { intestinal en pacientes médicos }\end{array}$ & Meta-análisis & RR 0,45 & $0,33-0,62$ \\
\hline Probióticos & Meta-análisis & RR 0,61 & $0,41-0,91$ \\
\hline
\end{tabular}

OR: odds ratio. RR: riesgo relativo. RRR: reducción de riesgo relativo. EPOC: enfermedad pulmonar obstructiva crónica. el trabajo habitual, con incorporación motivada de todos los integrantes del equipo de salud, capacitando, confeccionando guías clínicas, ejecutando rondas de chequeo diario y adhiriendo sobre $95 \%$ a los compromisos de las distintas prácticas seleccionadas.

Para el bundle del ventilador mecánico o bundle de NAVM, se eligen para evaluación algunas de las siguientes prácticas:

- Higiene de manos.

- Elevación de la cabeza del paciente sobre la cama 30 a $45^{\circ}$ (a menos que exista contraindicación).

- Cuidados en la fijación del TET y prevención de la extubación.

- Monitoreo del residuo gástrico cada cuatro horas si el paciente recibe alimentación enteral.

- Efectuar higiene de la cavidad oral cada dos horas (cepillado, aseo y uso clorhexidina). Cambio del equipo de aseo oral cada 24 hrs.

- Aspiración de hipofarinx previo a efectuar aspiración endotraqueal.

- Uso de tubos endotraqueales con sistema de aspiración continua.

- Mantener los circuitos del ventilador, equipos de aspiración, y máscara de ventilación manual fuera de contacto con la cama del paciente.

- Prevención de trombosis venosa profunda.

- Profilaxis de úlceras pépticas de estrés.

- Evaluación diaria de la posibilidad de extubación y disminución transitoria (programada) de la sedación.

Existen varias publicaciones que nos muestran la aplicación de distintos bundles y su efecto preventivo en las tasas de NAVM, por ejemplo, en adultos ${ }^{91-93}$ y en niños $^{94}$, y otras publicaciones que manifiestan algunos cuestionamientos aún por definir en la implementación y seguimiento de estos paquetes de medidas preventivas ${ }^{95}$.

En esta línea, una revisión sistemática reciente ${ }^{96}$, que incluyó cuatro ensayos clínicos que describieron importante reducción en tasas de NAVM con posterioridad a la aplicación de bundles, reveló, según los autores, errores metodológicos mayores en el diseño, reporte y resultados, concluyendo la necesidad de asegurar a futuro mejor información y nueva evaluación para su validación definitiva. A lo anterior se agrega el hecho de que a la fecha ninguno ha demostrado impacto en la evolución final de los pacientes. En la Tabla 2 se resume el impacto demostrado en disminuir la NAVM por la aplicación de “bundles".

Por lo tanto, aunque cada medida tiene una validez significativa por si misma en la prevención de NAVM, la aplicación de un grupo de tres a cinco de ellas indudablemente tiene el gran mérito de fomentar el trabajo en equipo. No obstante, la variabilidad en los distintos diseños de investigación y los errores metodológicos en 
algunas de éstas no nos permite avalar con el mayor nivel de evidencia estas prácticas. Así, este consenso apoya esta práctica con un nivel de evidencia y recomendación II B. Independientemente de lo anterior, el Comité Consultivo de IAAS de la Sociedad Chilena de Infectología propone considerar un bundle que incorpore las prácticas enunciadas en la Tabla 6.

\section{Conclusión}

Múltiples medidas han sido estudiadas en los últimos años para la prevención de la NAVM, muchas de las cuales han demostrado ser efectivas y con evidencia significativa (Tablas 2 y 3). Sin embargo, algunas éstas no han sido consideradas como recomendables por este consenso en vista de la poca aplicabilidad de la evidencia disponible a nuestro medio. Otras deben ser por ahora descartadas según los datos disponibles en la literatura médica (Tabla 4). No obstante, las experiencias de los paquetes de medidas, aunque sin una fuerte evidencia a la fecha, apuntan a que una de las cosas más importantes es la realización conjunta y ordenada de las mejores prácticas aplicadas al paciente con el fin de conseguir las menores tasas posibles de NAVM en nuestro medio (Tabla 5). La adherencia a normas y la aplicación irrestricta de la evidencia acumulada en los estudios de prevención parecen constituir el mejor camino para disminuir la morbi-mortalidad de nuestros pacientes hospitalizados en las unidades de cuidados intensivos.

\section{Resumen}

La neumonía asociada a ventilación mecánica ha persistido como una enfermedad relacionada a una alta mortalidad, a pesar de los avances que se han tenido en tratamiento. Es así que, hacer énfasis en la prevención de ésta, es fundamental para mejorar la morbi-mortalidad de las unidades de cuidados intensivos (UCIs). Los nuevos enfoques reportados en esta materia en los últimos años, hicieron necesaria la actualización de las recomendaciones hechas el año 2001. En vista de esto, se realizó una nueva búsqueda y análisis de la literatura científica. La información obtenida apoya diferentes intervenciones destacando: el uso de la posición semisentada a $45^{\circ}$; la higiene oral, de rutina, con clorhexidina; preferencia de la vía endotraqueal para intubación; realización de aspiración subglótica rutinaria; uso de las precauciones estándares; evitar el cambio rutinario de los circuitos de ventilación mecánica; y desarrollar paquetes de medidas ("bundles") que permitan organizar el trabajo en las UCIs. Algunas estrategias fueron recomendadas con datos de similar eficacia, pero mejor costo efectividad

\section{Tabla 4. Medidas sin impacto en la prevención de NAVM}

\begin{tabular}{|c|c|c|c|}
\hline Intervención & Estudio & Impacto en NAVM & IC95 \\
\hline \multicolumn{4}{|l|}{ No farmacológicas } \\
\hline Traqueostomía precoz & Meta-análisis & OR 0,90 & $0,66-1,21$ \\
\hline Aspiración abierta vs cerrada & Meta-análisis & OR 0,96 & $0,76-1,21$ \\
\hline Humidificación pasiva vs activa & Meta-análisis & OR 0,92 & $0,71-1,20$ \\
\hline $\begin{array}{l}\text { Alimentación gástrica o post- } \\
\text { pilórica }\end{array}$ & Meta-análisis & RR 1,28 & $0,91-1,80$ \\
\hline Filtros bacterianos & Ensayo randomizado & 2,4 vs 1,4 por 1.000 & No significativo \\
\hline \multicolumn{4}{|l|}{ Farmacológicas } \\
\hline $\begin{array}{l}\text { Profilaxis de úlceras de estrés con } \\
\text { bloqueadores } \mathrm{H} 2\end{array}$ & Meta-análisis & OR 1,25 & $0,78-2,00$ \\
\hline $\begin{array}{l}\text { Profilaxis de úlceras de estrés con } \\
\text { sucralfato vs antiácidos }\end{array}$ & Meta-análisis & OR 0,80 & $0,56-1,15$ \\
\hline $\begin{array}{l}\text { Profilaxis de úlceras de estrés con } \\
\text { sucralfato vs bloqueadores } \mathrm{H} 2\end{array}$ & Meta-análisis & OR 0,77 & $0,60-1,01$ \\
\hline
\end{tabular}

Tabla 5. Impacto en la incidencia de NAVM por el uso de bundles en la literatura científica

\begin{tabular}{|c|c|c|}
\hline Autor (ref) & $\begin{array}{l}\text { Tasa de NAVM previa a la } \\
\text { aplicación de "bundle" } \\
\text { (por } \mathbf{1 . 0 0 0} \text { días de ARM) }\end{array}$ & $\begin{array}{c}\text { Tasa posterior a la aplicación } \\
\text { de "bundle" } \\
\text { (por } 1.000 \text { días de ARM) }\end{array}$ \\
\hline Resar R (97) & 6,6 & 2,7 \\
\hline Berriel-Cass D (98) & 8,2 & 3,3 \\
\hline Youngquist (92) & 6,1 & 2,7 \\
\hline Unahalekhaka (99) & 13,3 & 8,3 \\
\hline
\end{tabular}

\section{Tabla 6. Propuesta Bundle Prevención NAVM del Comité Consultivo} IAAS- SOCHINF

1. Higiene de manos antes y después de procedimientos relacionados al paciente en ventilación mecánica

2. Elevación de la cabeza del paciente sobre la cama en 30 a 45 (a menos exista contraindicación).

3. Efectuar higiene de cavidad oral con cepillado, al menos cada 4 hrs. Uso de clorhexidina para el aseo, al menos 2 veces al día. Cambio del equipo de aseo oral cada 24 hrs.

4. Evaluación diaria de la posibilidad de extubación y disminución transitoria de la sedación programada 2 veces al día.

5. Aspiración de hipofarinx previo a efectuar aspiración endotraqueal o movilizar al paciente, o según disponibilidad uso de tubos traqueales con aspiración subglótica continua.

como: el uso de humidificadores higroscópicos; y el cambio de humidificadores cada 5 a 7 días. El uso de sistemas de aspiración abiertos o cerrados no afecta la incidencia de neumonía. Algunas recomendaciones no fueron incorporadas por falta de evidencia que asegurase su efectividad, datos controversiales o posibilidad dudosa de aplicación a nuestro país como la descontaminación intestinal selectiva. 


\section{Refererencias}

1.- Labarca J. Neumonía asociada a ventilación mecánica: Introducción. Rev. Chil. Infectol 2001; 18 (suppl 2): 39-40.

2.- Drakulovic M B, Torres A, Bauer T T, Nicolas J M, Nogue S, Ferrer M. Supine body position as a risk factor for nosocomial pneumonia in mechanically ventilated patients: a randomised trial. Lancet 1999; 354: 1851-8.

3.- Torres A, Serra-Batlles J, Ros E, Piera C, Puig de la Bellacasa J, Cobos A, et al. Pulmonary aspiration of gastric contents in patients receiving mechanical ventilation: The effect of body position. Ann Intern Med 1992; 116: 540-3.

4.- Alexiou V G, Ierodiakonou V, Dimopoulos G, Falagas M E. Impact of patient position on the incidence of ventilator-associated pneumonia: a meta-analysis of randomized controlled trials. J Crit Care 2009; 24 (4): 515-22.

5.- Van Nieuwenhoven C A, Vandenbroucke-Grauls C, van Tiel F H, Joore H C, van Schijndel R J, van der Tweel I, et al. Feasibility and effects of the semirecumbent position to prevent ventilator-associated pneumonia: a randomized study. Crit Care Med 2006; 34 (2): 396-402.

6.- Goldhill D R, Imhoff M, McLean B, Waldmann C. Rotational bed therapy to prevent and treat respiratory complications: A review and meta-analysis. Am J Crit Care 2007; 16 (1): 50-61.

7.- ASHP Commission on Therapeutics. ASHP therapeutic guidelines on stress ulcer prophylaxis. ASHP Commission on Therapeutics and approved by the ASHP Board of Directors on November 14, 1998. Am J Health Syst Pharm 1999; 56: 347-79.

8.- Cook D J, Reeve B K, Guyatt G H, Heyland D K, Griffith L E, Buckingham L, et al. Stress ulcer prophylaxis in critically ill patients: resolving discordant meta-analyses. JAMA 1996; 275 (4): 308-14.

9.- Quenot J P, Thiery H, Barbar S. When should stress ulcer prophylexis be used in the ICU? Curr Opin Crit Care 2009; 15 (2): 139-43.

10.- Cook D J. Stress ulcer prophylaxis: gastrointestinal bleeding and nosocomial pneumonia: best evidence synthesis. Scand J Gastroenterol Suppl 1995; 210: 48-52.

11.- Cook D J, Guyatt G H, Marshall J, Leasa D, Fuller H, Hall R, et al for the Canadian Critical Care Trials Group. A comparison of sucralfate and ranitidine for prevention of upper gastrointestinal bleeding in patients requiring mechanical ventilation. N Engl J Med 1998; 338: 791-7.

12.- Levy M J, Seelig C B, Robinson N J, Ranney J E. Comparison of omeprazole and ranitidine for stress ulcer prophylaxis. Dig Dis Sci 1997; 42: 1255-9.

13.- Azevedo J R, Soares M G, Silva G, Palacio G.
Prevention of stress ulcer bleeding in high risk patients: comparison of three drugs [abstract]. Crit Care Med 1999; 27: A41.

14.- Yildizdas D, Yapicioglu H and Yilmaz H L. Occurrence of ventilator-associated pneumonia in mechanically ventilated pediatric intensive care patients during stress ulcer prophylaxis with sucralfate, ranitidine, and omeporazole. J Crit Care 2002; 17 (4): 240-5.

15.- Kahn J, Doctor J and Rubenfeld G. Stress ulcer prophylaxis in mechanically ventilated patients: integrating evidence and judgment using a decision analysis. Intensive Care Med 2006; 32 : 1151-8.

16.- Hernández P G, Dalmazzo A R, De la Cerda S G, Saavedra M C, Calvo A M. Prevención de la neumonía asociada a ventilación mecánica. Rev Chil Infectol 2001; 18 (suppl 2): 66-76.

17.- Marik P E, Zaloga G P. Gastric versus postpiloric feeding: a systemayic review. Crit Care 2003; v7(3): vR46-51

18.- Ho K M, Dobb G J, Webb S A. A comparison of early gastric and post-piloric feeding in critically ill patients: a meta-analysis. Intensive Care Med 2006; 32 (5): 639-49.

19.- Heyland D, Drover J, MacDonald S, Novak F, Lam M. Effect of postpyloric feeding on gastroesophageal regurgitation and pulmonary micro aspiration: results of a randomized controlled trial. Crit Care Med 2001; 29: 1495 510 .

20.- Ibrahim E, Mehringer L, Prentice D, Sherman G, Schaiff H R, Fraser V, et al. Early versus late enteral feeding of mechanically ventilated patients: results of a clinical trial. J Parenter Enteral Nutr 2002; 26: 174-81.

21.- Taylor N, Van Saene H K F, Abella A, Silvestri L, Vucic M, Peric M. Descontaminación digestiva selectiva. ¿Por qué no aplicamos la evidencia en la práctica clínica? Med Intensiva 2007; 31 (3): 136-45.

22.- Liberati A, D’Amico R, Pifferi S, Torri V, Brazzi L, Parmelli E. Antibiotic prophylaxis to reduce respiratory tract infections and mortality in adults receiving intensive care. Cochrane Database of Systematic Reviews. In: The Cochrane Library, Issue 12, Art. No. CD000022. DOI:10.1002/14651858.CD000022.pub3.

23.- de Smet A M, Kluytmans J A, Cooper B S, Mascini E M, Benus R F, van der Werf T S, et al. Decontamination of the digestive tract and oropharynx in ICU patients. N Engl J Med 2009; 360 (1): 20-31.

24.- Blair P, Rowlands B J, Lowry K, Webb H, Armstrong P, Smilie J. Selective decontamination of the digestive tract: a stratified, randomized, prospective study in a mixed intensive care unit. Surgery 1991; 110 (2): 303-9; Discussion 309-10.

25.- Gastinne H, Wolff M, Delatour F, Faurisson F, Chevret $\mathrm{S}$. A controlled trial in intensive care units of selective decontamination of the digestive tract with nonabsorbable antibiotics. N Engl J Med 1992; 326: 594-9.

26.- Lingnau W, Berger J, Javorsky F, Fille M, Allerberger F, Benzer H. Changing bacterial ecology during a five-year period of selective intestinal decontamination. J Hosp Infect. 1998; 39 (3): 195-206.

27.- Quinio B, Albanèse J, Bues-Charbit M, Viviand X, Martin C. Selective decontamination of the digestive tract in multiple trauma patients. A prospective double-blind, randomized, placebo-controlled study. Chest 1996; 109 (3): 765-72.

28.- Rocha L A, Martín M J, Pita S, Paz J, Seco C, Margusino L, et al. Prevention of nosocomial infection in critically ill patients by selective decontamination of the digestive tract. A randomized, double blind, placebo-controlled study. Intensive Care Med 1992;18 (7): 398-404.

29.- Sánchez García M, Cambronero Galache J A, López Díaz J, Cerdá Cerdá E, Rubio Blasco J, Gómez Aguinaga M A, et al. Effectiveness and cost of selective decontamination of the digestive tract in critically ill intubated patients. A randomized, double-blind, placebo-controlled, multicenter trial. Am J Respir Crit Care Med 1998; 158 (3): 908-16.

30.- Sánchez García M, De la Torre M A, Morales G, Peláez B, Tolón M J, Domingo S, et al. Clinical outbreak of linezolid-resistant Staphylococcus aureus in an intensive care unit. JAMA 2010; 303 (22): 2260-4.

31.- Schultz M J, de Jonge E, Kesecioglu J. Selective decontamination of the digestive tract reduces mortality in critically ill patients. Critical Care 2003, 7: 107-10.

32.- Kollef M, Pittet D, Sánchez-García M, Chastre J, Fagon J Y, Bonten M, et al. A randomized double-blind trial of iseganan in prevention for ventilador-associated pneumonia. Am J Respir Crit Care Med 2006; 173: 91-7.

33.- Seguin P, Tanguy M, Laviolle B, Tirel O, Mallédant Y. Effect of oropharyngeal decontamination by povidone-iodine on ventilator-associated pneumonia in patients with head trauma. Crit Care Med 2006; 34 (5): 1514-9

34.- Mori H, Hirasawa H, Oda S, Shiga H, Matsuda $\mathrm{K}$, Nakamura M. Oral care reduces incidence of ventilator-associated pneumonia in ICU populations. Intensive Care Med 2006; 32: 2306.

35.- Sona C, Zack J, Schallom M, McSweeney M, McMullen K, Thomas J, et al. The impact of a simple, low-cost oral care protocol on ventilator-associated pneumonia rates in a surgical intensive care unit. J Intensive Care Med; 24 (1): 54-62.

36.- Panchabhai T, Dangayach N, Krishnan A, Kothari V, Karnad D. Oropharyngeal cleansing with $0.2 \%$ chlorhexidine for prevention of 
nosocomial pneumonia in critically ill patients. An open-label randomized trial with $0.01 \%$ potassium permanganate as control. Chest 2009 135: 1150-6.

37.- Chlebicki M, Safdar N. Topical chlorhexidine for prevention of ventilator-associated pneumonia: A meta-analysis. Crit Care Med 2007; 35 (2): 595-602

38.- Tantipong H, Morkcharconpong C, Jaiyindee S, Thamlikitkul V. Randomized controlled trial and meta-analysis of oral decontamination with $2 \%$ chlorhexidine solution for the prevention of ventilator-associated pneumonia. Infect Control Hosp Epidemiol 2008; 29: 131-6.

39.- Chan E, Ruest A, Meacle M, Cook D. Oral decontaminación for prevention of pneumonia in mechanically ventilated adults: systematic review and meta-analysis. Br Med J 2007; 334 : 889.

40.- Valencia M, Ferrer M, Farre R, Navajas D, Badia JR, Nicolas JM, et al. Automatic control of tracheal tube cuff pressure in ventilated patients in semirecumbent position: a randomized trial. Crit Care Med 2007; 35(6): 1543-9.

41.- Holzapfel L, Chastang C, Demingeon G, Bohe J, Piralla B, Coupry A. A randomized study assessing the systematic search for maxillary sinusitis in nasotracheally mechanically ventilated patients: influence of nosocomial maxillary sinusitis on the occurrence of ventilator-associated pneumonia. Am J Respir Crit Care Med 1999; 159: 695-701.

42.- Holzapfel L, Chevret S, Madinier G, Ohen F, Demingeon G, Coupry A, et al. Influence of long-term oro- or nasotracheal intubation on nosocomial maxillary sinusitis and pneumonia: results of a prospective, randomized clinical trial. Crit Care Med 1993; 21: 1132-8.

43.- Salord F, Gaussorgues P, Marti-Flich J, Sirodot M, Allimant C, Lyonnet D, et al. Nosocomial maxillary sinusitis during mechanical ventilation: a prospective comparison of orotracueal versus the nasotracheal route of intubation. Intensive Care Med 1990;16: 390-3

44.- Kollef MH, Afessa B, Anzueto A, Veremakis C, Kerr KM, Margolis BD, et al; NASCENT Investigation Group. Silver-coated endotrachea tubes and incidence of ventilator-associated pneumonia: the NASCENT randomized trial. JAMA 2008; 300 (7): 805-13.

45.- Dezfulian C, Shojania K, Collard HR, Kim HM, Matthay MA, Saint S. Subglottic secretion drainage for preventing ventilator-associated pneumonia: a meta-analysis. Am J Med 2005; b118 (1):b11-8.

46.- Caruso P, Denari S, Ruiz S A, Demarzo S E, Deheinzelin D. Saline instillation before tracheal suctioning decreases the incidence of ventilator-associated pneumonia. Crit Care Med 2009; 37 (1): 32-8.
47.- Deppe S A, Kelly J W, Thoi L L, Chudy J H, Longfield R N, Duccy J P, et al. Incidence of colonization, nosocomial pneumonia and mortality in critically ill patients using a Trach Care closed-suction system versus an opensuction system: Prospective, randomized study. Crit Care Med 1990; 18 (12): 1389-93.

48.- Topeli A, Harmanci A, Cetinkaya Y, Akdeniz S, Unal S. Comparison of the effect of closed versus open endotracheal suction systems on the development of ventilator-associated pneumonia. J Hosp Infect 2004; 58 (1): 14-9.

49.- Johnson K L, Kearney P A, Johnson S B, Niblett J P, MacMillan N L, McClain R E. Closed versus open endotracheal suctioning: Costs and physiologic consecuences. Crit Care Med 1994; 22: 658-66.

50.- Jongerden I, Rovers M, Grypdonck M, Bonten M. Open and closed endotracheal suction systems in mechanically ventilated intensive care patients: A meta-analysis. Crit Care Med 2007; 35 (1): 260-70.

51.- Woodgate P G, Flenady V. Tracheal suctioning without disconnection in intubated ventilated neonates. The Cochrane Library, Issue 3, 2001. Oxford: Update Software.

52.- Kollef M H, Prentice D, Shapiro S D, Fraser V J, Silver P, Trovillion E, et al. Mechanical ventilation with or without daily change of in-line suction catheters. Am J Respir Crit Care Med. 1997; 156 (2 Pt 1): 466-72.

53.- American Thoracic Society; Infectious Diseases Society of America. Guidelines for the management of adults with hospital-acquired, ventilator-associated, and healthcare-associated pneumonia. Am J Respir Crit Care Med 2005; 171(4): 388-416.

54.- Rotstein C, Evans G, Born A, Grossman R, Light R B, Magder S, et al. Clinical practice guidelines for hospital-acquired pneumonia and ventilator-associated pneumonia in adults. Can J Infect Dis Med Microbiol 2008; 19 (1): 19-53.

55.- Koenig S M, Truwit J D. Ventilator-associated pneumonia: diagnosis, treatment, and prevention. Clin Microbiol Rev 2006; 19 (4): 637-57.

56.- Gallagher J, Strangeways J E M, Allt-Graham J. Contamination control in long term ventilation. Anaesthesia 1987; 42: 476-81.

57.- Llorente L, Lecuona M, Malaga J, Revert C, Mora M L, Sierra A. Bacterial filters in respiratory circuits. An innecessary cost? Crit Care Med 2003; 31: 21-6.

58.- Kollef M H, Shapiro S D, Fraser V J, Silver P, Murphy D M, Trovillion E, et al. Mechanical ventilation with or without 7-day circuit changes. A randomized controlled trial. Ann Intern Med 1995; 123 (3): 168-74.

59.- Lorente L, Lecuona M, Galván R, Ramos M J, Mora M L, Sierra A. Periodically changing ventilator circuits is not necessary to prevent ventilator-associated pneumonia when a heat and moisture exchanger is used. Infect Control Hosp Epidemiol 2004; 25: 1077-82.

60.- Kollef M H. Prolonged use of ventilator circuits and ventilator-associated pneumonia: a model for identifying the optimal clinical practice. Chest 1998; 113: 267-9.

61.- Han J, Liu Y. Effect of ventilator circuit changes on ventilator-associated pneumonia: a systematic review and meta-analysis. Respir Care 2010; 55 (4): 467-74.

62.- Cook D, De Jonghe B, Brochard L, Brun-Buisson C. Influence of airway management on ventilator-associated pneumonia: evidence from randomized trials. JAMA 1998; 279 (10): 781-7.

63.- Bench S. Humidification in the long-term ventilated patient; a systematic review. Intensive Crit Care Nurs 2003; 19 (2): 75-84.

64.- Kelly M, Gillies D, Todd DA, Lockwood C. Heated humidification versus heat and moisture exchangers for ventilated adults and children. Cochrane Database Syst Rev 2010; (4): CD004711.

65.- Davis K Jr, Evans S L, Campbell R S, Johannigman J A, Luchette F A, Porembka D $\mathrm{T}$, et al. Prolonged use of heat and moisture exchangers does not affect device efficiency or frequency rate of nosocomial pneumonia. Crit Care Med 2000; 28 (5): 1412-8.

66.- Thomachot L, Leone M, Razzouk K, Antonini F, Vialet R, Martin C. Randomized clinical trial of extended use of a hydrophobic condenser humidifier: 1 vs 7 days. Crit Care Med 2002; 30 (1): 232-7.

67.- Gallagher J, Strangeways J E M, Allt-Graham J. Contamination control in long term ventilation. Anaesthesia 1987; 42: 476-81

68.- Harstein A I, Rashad A L, Liebler J M, Actis L A, Freeman J, Rourke J W Jr, et al. Multiple intensive care units outbtreak of Acinetobacter calcoaceticus subspecies anitratus respiratory infection and colonization associated with contaminated, reusable, ventilator circuits and resuscitation bags. Am J Med 1988; 85: 624-31.

69.- Weber D J, Wilson M B, Rutala W A, Thomann C A. Manual ventilation bags as a source for bacterial colonization of intubated patients. Am Rev Respir Dis 1990; 142: 892-4.

70.- Navarrete M, Calvo M, Gutiérrez A, Silva R, García C, Cea M, et al. Fatiga del material de los sistemas de ventilación mecánica como factor de riesgo en neumonía asociada a ventilación mecánica. Rev Chil Infectol 2004; 21 (1): 9-16.

71.- Patman S, Jenkins S, Stiller K. Physiotherapy does not prevent, or hasten recovery from, ventilator-associated pneumonia in patients with acquired brain injury. Intensive Care Med 2009; 35(2): 258-65.

72.- Patman S, Sanderson D, Blackmore M. 
Physiotherapy following cardiac surgery: is it necessary during the intubation period? Aust J Physiother 2001; 47 (1): 7-16.

73.- Pattanshetty R B, Gaude G S. Effect of multimodality chest physiotherapy in prevention of ventilator-associated pneumonia: A randomized clinical trial. Indian J Crit Care Med 2010; 14 (2): 70-6.

74.- Aboussouan LS, Ricaurte B. Noninvasive positive pressure ventilation: Increasing use in acute care. Cleve Clin J Med 2010; 77 (5): $307-1$

75.- Boles J M, Bion J, Connors A, Herridge M, Marsh B, Melot C, et al. Weaning from mechanical ventilation. Eur Respir J 2007; 29 (5): 1033-5.

76.- Burns K E, Adhikari N K, Keenan S P, Meade M. Use of non-invasive ventilation to wean critically ill adults off invasive ventilation: meta-analysis and systematic review. Br Med J 2009; 338: b1574. doi: 10.1136/bmj.b1574.

77.- Griffiths J, Barber V S, Morgan L, Young J D. Systematic review and meta-analysis of studies of the timing of tracheostomy in adult patients undergoing artificial ventilation. Br Med J 2005; 330 (7502): 1243. Epub 2005 May 18.

78.- Chao Y F, Chen Y Y, Wang K W, Lee R P, Tsai $\mathrm{H}$. Removal of oral secretion prior to position change can reduce the incidence of ventilatorassociated pneumonia for adult ICU patients: a clinical controlled trial study. J Clin Nurs 2009; 18 (1): $22-8$.

79.- Siempos I I, Ntaidou T K, Falagas M E. Impact of the administration of probiotics on the incidence of ventilator-associated pneumonia: a meta-analysis of randomized controlled trials. Crit Care Med 2010; 38 (3): 954-62.

80.- Dhand R. The role of aerosolized antimicrobials in the treatment of ventilator-associated pneumonia. Respir Care 2007; 52(7): 866-84.

81.- Greenfield S, Teres D, Bushnell L S, HedleyWhyte J, Feingold D S. Prevention of gramnegative bacillary pneumonia using aerosol polymyxin as prophylaxis. I. Effect on the colonization pattern of the upper respiratory tract of seriously ill patients. J Clin Invest 1973; 52 (11): 2935-40.

82.- Feeley T W, Du Moulin G C, Hedley-Whyte J, Bushnell L S, Gilbert J P, Feingold D S. Aerosol polymyxin and pneumonia in seriously ill patients. N Engl J Med 1975; 293 (10): 471-5.

83.- Klick J M, du Moulin G C, Hedley-Whyte J, Teres D, Bushnell L S, Feingold D S. Prevention of gram-negative bacillary pneumonia using polymyxin aerosol as prophylaxis. II. Effect on the incidence of pneumonia in seriously ill patients. J Clin Invest 1975; 55 (3): 514-9.

84.- Klastersky J, Huysmans E, Weerts D, Hensgens C, Daneau D. Endotracheally administered gentamicin for the prevention of infections of the respiratory tract in patients with tracheostomy: a double-blind study. Chest 1974; 65 (6): 650-4.

85.- Lode H, Hoffken G, Kemmerich B, Schaberg T. Systemic and endotracheal antibiotic prophylaxis of nosocomial pneumonia in ICU. Intensive Care Med 1992;18 Suppl 1:S24-S27.

86.- Wood G C, Boucher B A, Croce M A, Hanes S D, Herring V L, Fabian T C. Aerosolized ceftazidime for prevention of ventilatorassociated pneumonia and drug effects on the proinflammatory response in critically ill trauma patients. Pharmacotherapy 2002; 22 (8): 972-82.

87.- Claridge J A, Edwards N M, Swanson J, Fabian T C, Weinberg J A, Wood C, et al. Aerosolized ceftazidime prophylaxis against ventilator-associated pneumonia in high-risk trauma patients: results of a double-blind randomized study. Surg Infect (Larchmt) 2007; 8 (1): 83-90.

88.- Falagas M E, Siempos I I, Bliziotis I A, Michalopoulos A. Administration of antibiotics via the respiratory tract for the prevention of ICU-acquired pneumonia: a meta-analysis of comparative trials. Crit Care 2006; 10 (4): R123.

89.- Rathgeber J, Zielmann S, Panzer C, Burchardi $\mathrm{H}$. Prevention of pneumonia by endotracheal micronebulization of tobramycin. Anasthesiol Intensive Med Notfallmed Schmerzther 1993, 28:23-29 (Abstract).

90.- Institute for Healthcare Improvement. http:// www.ihi.org.

91.- Zilbergberg M D, Shorr A F, Koleff M H. Implementing quality improvements in the intensive care units: ventilator bundle as an example. Crit Care Med 2009; 3791: 305-9.

92.- Youngquist P, Carroll M, Farber M, Macy D, Madrid P, Ronning J et al. Implementing a ventilator bundle in a community hospital. Jt Comm J Qual Patient Saf 2007; 33: 219-25.

93.- Hawe C, Ellis K, Cairns C, Longmate A. Reduction of ventilator-associated pneumonia: active versus passive guideline implementation. Intensive Care Med 2009;35: 1180-6.

94.- Brilli R J, Sparling K W, Lake M R, Butcher J, Myers S S, Clark M D, et al. The business case for preventing ventilator-associated pneumonia in pediatric intensive care unit patients. Jt Comm J Qual Patient Saf. 2008; 34: 629-38.

95.- Rello J, Hartmut L, Cornaglia G, Masterton R. A European care bundle for prevention of ventilator-associated pneumonia. Intensive Care Med 2010; 36: 773-80.

96.- Wip Ch, Napolitano L. Bundles to prevent ventilator-associated pneumonia:how valuable are they?. Curr Opin Infect Dis 2009; 22: 15966.

97.- Resar R, Pronovost P, Haraden C, Simmonds T, Rainey T, Nolan T. Using a bundle approach to improve ventilator care processes and reduce ventilator-associated pneumonia. Jt Comm J Qual Patient Saf 2005; 31 (5): 243-8.

98.- Berriel-Cass D, Adkins F W, Jones P, Fakih M G. Eliminating nosocomial infections at Ascension Health. Jt Comm J Qual Patient Saf 2006; 32 (11): 612-20.

99.- Unahalekhaka A, Jamulitrat $\mathrm{S}$, Chongsuvivatwong V, Øvretveit J. Using a collaborative to reduce ventilator-associated pneumonia in Thailand. Jt Comm J Qual Patient Saf 2007; 33 (7): 387-94. 